\title{
Desenvolvimento da Compreensão Leitora através do Monitoramento da Leitura
}

\section{Improving Reading Comprehension by Developing Monitoring Strategies}

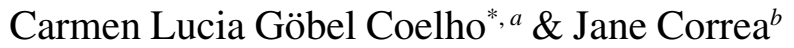 \\ ${ }^{a}$ Colégio Nossa Senhora das Dores, Rio de Janeiro, Brasil \\ $\&{ }^{b}$ Universidade Federal do Rio de Janeiro, Rio de Janeiro, Brasil
}

\begin{abstract}
Resumo
Este estudo teve como objetivo examinar o progresso da compreensão leitora através do desenvolvimento da habilidade de monitoramento a partir do emprego do paradigma de detecção de erros. Adolescentes distribuídos nos grupos experimental e controle realizaram as tarefas de monitoramento e leitura (teste de Cloze) como pré-teste e pós-teste, tendo sido controladas: habilidade verbal, atenção e memória de trabalho. Os grupos não diferiram em suas habilidades lingüístico-cognitivas, nem em seu desempenho nas tarefas do pré-teste. Após a intervenção, o grupo experimental foi significativamente melhor do que o grupo controle nas tarefas de leitura e de monitoramento. Tais evidências sugerem que o progresso no desenvolvimento da compreensão de texto está relacionado à eficiência com que os adolescentes monitoram sua leitura.
\end{abstract}

Palavras-chave: Monitoramento; Intervenção; Leitura; Adolescente.

\begin{abstract}
The present study examines whether the development of monitoring strategies improves textual comprehension skills using an error detection methodology for checking it. Adolescents distributed into experimental and control groups were presented to the monitoring and cloze tasks of pre- and post-tests where tasks like verbal ability, attention and working memory were controlled. The experimental and control groups did not differ in their linguistic-cognitive abilities or in their performance in the pre-test tasks. However, the performance of the experimental group was significantly better than the control group in the reading and monitoring tasks carried out after the intervention. The evidences found in this study suggest that text comprehension can be improved by the efficiency adolescents monitor their reading process.

Keywords: Monitoring; Intervention; Reading; Adolescent.
\end{abstract}

A leitura está presente no cotidiano das sociedades letradas, sendo o seu domínio fundamental como fator de integração social. Através da leitura, novas aprendizagens são construídas, principalmente no espaço escolar, para diferentes disciplinas do currículo. O desenvolvimento da habilidade de leitura, por sua vez, requer um aprendizado sistemático (Colomer \& Camps, 2002; Spinillo, 1994), o que torna a escola um espaço privilegiado de investigação e de intervenção no estudo da compreensão textual.

A leitura envolve um processo de interação entre autor e leitor, que, longe de ser apenas um receptor da mensagem, precisa realizar um trabalho ativo para a compre- ensão do texto (Ferreiro, 1985). Esse processo inclui tanto os conhecimentos prévios ao ato de ler, como o desenvolvimento de habilidades lingüístico-cognitivas relacionadas à leitura. Ler envolve raciocinar com as palavras e seus significados, bem como a interpretação da mensagem explícita e a sua integração com o conhecimento nela implícito, num processo contínuo de construção e ressignificação do texto lido (Colomer \& Camps, 2002). Por outro lado, o sentido do texto não pode ser apreendido sem que o leitor tenha o domínio das convenções do sistema de escrita. Tal conhecimento permite a ele extrair significados a partir da leitura que realiza das palavras no texto (Oakhill, 2005). De acordo com o modelo
* Endereço para correspondência: Colégio Nossa Senhora das Dores, Rua Augusto Spinelli, 75, Centro, Nova Friburgo, RJ, Brasil, CEP 28600-000. E-mail: carmen_gobel@yahoo.com.br e janecorrea@rjnet.com.br $\mathrm{O}$ presente artigo deriva da dissertação de mestrado apresentada ao Programa de Pós-Graduação em Psicologia da Universidade Federal do Rio de Janeiro (UFRJ) pela primeira autora sob orientação da segunda autora.
Agradecemos ao Colégio Nossa Senhora das Dores pelo apoio e entusiasmo com que nos acolheram; aos responsáveis pela confiança em nosso trabalho e aos jovens pelo muito que generosamente nos ensinaram. Nossos agradecimentos ainda à Fundação de Amparo à Pesquisa do Estado do Rio de Janeiro (Faperj) e ao Conselho Nacional de Desenvolvimento Científico e Tecnológico (CNPq). 
simples de leitura, ler implica simultaneamente os processos de decodificação e compreensão (Oakhill, 2005).

Para compreender um texto, é preciso que o leitor estabeleça relações de sentido que vão sendo construídas de forma crescente. O leitor constrói uma representação mental do texto lido (Kintsch, 1988) a partir da convergência entre as idéias do autor, através do texto escrito, e as idéias do leitor, por meio de seu conhecimento prévio (Kintsch \& van Dijk, 1978). A compreensão vai sendo produzida, então, por meio de diferentes níveis de representação elaborados durante a leitura do texto. Kintsch e van Dijk (1978) propõem que o processamento do texto seja feito em ciclos, devido às limitações da memória de trabalho, que não suportaria operar com todo o volume de informações numa única vez. O leitor vai construindo proposições que contêm as idéias principais retiradas das informações extraídas do texto. Essas informações são mantidas até o final de cada ciclo. Esses ciclos correspondem a uma série de proposições que são ordenadas de acordo com seu surgimento no texto. As idéias, contidas nas proposições, vão sendo substituídas por outras, até que se construa o significado global do texto. Dessa forma, em cada ciclo, as informações novas alteram as representações anteriores, mudando e enriquecendo gradualmente o texto que está sendo lido. A compreensão textual é, portanto, um processo de construção e integração. Com o desenvolvimento de habilidades lingüístico-cognitivas relacionadas à leitura, o leitor vai adquirindo recursos que lhe permitem avançar de um nível mais básico de leitura, como decodificar e entender o significado de palavras e frases simples, até um nível mais complexo de compreensão leitora (Kinnunen \& Vauras, 1995).

Leitores habilidosos possuem habilidades metacognitivas sofisticadas (Kinnunen \& Vauras, 1995). Habilidades metacognitivas permitem ao sujeito conhecer e utilizar seus recursos cognitivos, assim como manipular meios mais adequados para a execução de uma tarefa ou emprego de um dado procedimento (Ribeiro, 2003). O leitor, ao fazer uso de habilidades metacognitivas, emprega mecanismos de autorregulação, o que inclui a habilidade para monitorar a compreensão durante o processo de integração da informação na leitura (Kinnunen \& Vauras, 1995).

O monitoramento envolve dois processos básicos: a detecção e a regulação (Hacker, 1997; Kinnunen \& Vauras, 1995; Oakhill, Hartt, \& Samols, 2005). Leitores habilidosos utilizam o monitoramento de forma cuidadosa e metódica, detectando inconsistências no texto, mesmo que tais inconsistências estejam em sentenças distantes (Oakhill et al., 2005). Além disso, detectam e solucionam dificuldades surgidas na leitura em todos os níveis de processamento (Oakhill et al., 2005).

Problemas observados no processo de leitura podem ser gerados tanto no nível do léxico como por inconsistências ou incoerências detectadas entre as sentenças no próprio texto (Baker, 1986). A avaliação da consistência interna responde por um nível mais sofisticado de monitoramento da leitura, já que requer do leitor a integração das proposições do texto escrito. Reconhecer a dificuldade na compreensão de uma tarefa, ou tornar-se consciente de que não se compreendeu algo, é uma das habilidades que parece distinguir leitores habilidosos dos menos habilidosos (Brown, 1978).

Kinnunen e Vauras (1995) propõem que o desenvolvimento das habilidades de compreensão está diretamente ligado ao desenvolvimento da habilidade para monitorar textos. Assim sendo, o treino no monitoramento da compreensão pode, portanto, melhorar o desempenho dos sujeitos para compreender textos, em comparação com aqueles que não receberam tal treinamento (Miller, 1985). Foram encontradas correlações positivas e significativas entre instrução e o tipo de correção de determinado tipo de erro. Instruções voltadas para que o leitor procure erros de sentido não interferem na detecção de erros de ortografia e gramática, porém, instruções usadas para procurar erros ortográficos e de gramática interferem na detecção de erros de sentido (Hacker, 1997). Isso ocorre porque o leitor, ao enfatizar a detecção e correção de erros situados num nível mais básico de leitura, deixa de construir o sentido global do texto. Muitos problemas encontrados no texto podem ser monitorados e controlados se o texto for lido com o objetivo de ser compreendido e não de ser decifrado (Oakhill \& Garnham, 1988). Segundo Hacker (1997), se os leitores forem encorajados a monitorar e controlar sua compreensão usando padrões de avaliação semântica de alto nível, será possível garantir o monitoramento e controle nos níveis mais baixos, relacionados ao domínio dos aspectos formais do sistema de escrita.

Thiede, Anderson e Therriault (2003) sugerem que o monitoramento é fundamental para a aprendizagem realizada por meio de textos escritos, regulando o estudo e o tempo necessário para realização da aprendizagem. Para isso, faz-se necessário que o sujeito monitore o quanto entendeu, ou não, do que está lendo, para terminar seu estudo ou continuá-lo. O monitoramento é uma habilidade metacognitiva que está relacionada com a aprendizagem e a rememoração (Brown, 1978; Brown, Bransford, Ferrara, \& Campione, 1983). Ao fazer uso do monitoramento, o leitor competente percebe o quanto o texto foi bem entendido ou não, através de uma série de pistas que permitem esse julgamento (Thiede et al., 2003). Podem ser citadas, por exemplo, as situações em que o leitor avalia se o texto foi processado facilmente ou não, ou o quanto ele domina o conteúdo lido, entre outras possibilidades. Por isso, é possível que a habilidade do sujeito em monitorar seu aprendizado promova a base decisória sobre qual o assunto estudar ou o quanto é necessário estudar. Assim, quanto mais preciso for o monitoramento, mais possibilidade tem o aprendiz de regular eficazmente sua leitura e seu aprendizado. No entanto, 
apesar das evidências presentes na literatura sobre a influência do monitoramento sobre a compreensão leitora, não é de todo clara a forma como estas habilidades se relacionam. É possível admitir, por exemplo, a hipótese de ser a compreensão leitora essencial para o monitoramento, e não o contrário (Cain \& Oakhill, 2004).

Nesse sentido, o presente trabalho pretende examinar a influência do monitoramento no processo da compreensão textual por adolescentes alunos do ensino médio. Especificamente na adolescência, na passagem do $9^{\circ}$ ano do ensino fundamental para o $1^{\circ}$ ano do ensino médio, há um aumento do nível de complexidade nos textos escritos, o qual nem sempre é acompanhado do necessário desenvolvimento das habilidades de leitura dos jovens (Instituto Nacional de Estudos e Pesquisas Educacionais Anísio Teixeira [INEP], \& Ministério da Educação [MEC], 2001). Parte-se da hipótese de que a habilidade de monitoramento seja passível de treinamento, e que seria possível, através de estratégias de intervenção no monitoramento da leitura, melhorar a habilidade para compreender textos acadêmicos, utilizando como procedimento o paradigma de detecção de erros.

\section{Método}

\section{Participantes}

Participaram dessa pesquisa 62 jovens, alunos do primeiro ano do ensino médio, de uma escola particular do município de Nova Friburgo no estado do Rio de Janeiro, com idades entre 14 e 17 anos $(M=15$ anos e 8 meses e $D P=8$ meses). Visando a respeitar as práticas escolares e não comprometer a rotina dos alunos na escola, os adolescentes foram alocados, respectivamente, nos grupos experimental (GE) e de controle (GC), de acordo com a distribuição de turmas da escola, uma vez que a designação de formação das turmas pela escola não obedecia à hierarquização de desempenho acadêmico ou qualquer outro critério que pudesse comprometer a investigação. Todos os alunos foram informados sobre a pesquisa através de comunicação oral e foram convidados a participar voluntariamente do estudo.

\section{Tarefas}

Os textos acadêmicos escolhidos para avaliação da compreensão leitora e do monitoramento, bem como a realização das tarefas da intervenção, foram retirados dos textos do livro "História 8 - Ensino fundamental. Projeto Araribâ", utilizado no $9^{\circ}$ ano do ensino fundamental (Apolinário, 2006).

\section{Leitura}

Para avaliar a compreensão leitora foi utilizada a tarefa de Cloze (Boruchovitch, Santos, \& Oliveira, 2007; Cain \& Oakhill, 2004; Oliveira, Boruchovitch, \& Santos, 2007). Foram utilizados, no pré-teste e no pós-testes, textos com 250 palavras em média, tendo como temática o meio ambiente. Cada quinto vocábulo do texto foi sistematicamente omitido. Os jovens deveriam preencher as lacunas com as palavras que achassem mais adequadas para a coerência e compreensão do texto. O coeficiente de confiabilidade da tarefa (Alpha de Cronbach) foi para o pré-teste $0,80 \mathrm{e}$, para o pós-teste, 0,84 .

\section{Monitoramento}

Para as tarefas de monitoramento (pré-teste, pós-teste e intervenção), foi utilizada a metodologia do paradigma de detecção de erros (Baker, 1986; Hacker, 1997; Kinnunen \& Vauras, 1995; Oakhill et al., 2005), segundo a qual são feitas inserções de transgressões no texto em ambos os padrões, lexical e de consistência interna. O padrão lexical avalia a compreensão no nível lingüístico. Dessa forma, podem ser detectadas palavras sem sentido, raras ou que contenham transgressões ortográficas ou gramaticais. O padrão de consistência interna se refere à avaliação de contradições geradas dentro do texto, oriundas da inclusão de palavras ou expressões que trazem incoerência ao texto.

Os textos continham de 500 a 600 palavras. Foram incluídos 18 itens de inconsistência (nove erros lexicais e nove de consistência interna) ao longo dos textos em vários parágrafos. A inclusão dos itens de inconsistência em parágrafos e não em frases deve-se ao fato de que o parágrafo é uma unidade de sentido e processamento mais ampla que uma frase. Para evitar que o conhecimento do número de erros usados na intervenção afetasse o desempenho dos jovens, foram incluídos mais dois erros na tarefa de monitoramento do pós-teste: um lexical e outro relacionado à consistência interna. Esperava-se, para os erros lexicais, a correção da ortografia, concordância verbal ou pontuação enquanto, e para os erros de consistência interna, a inserção da palavra igual à do texto original ou sinônima, de forma a restabelecer o sentido do texto.

Os textos foram lidos por três juízes que classificaram os itens inseridos de acordo com os padrões de consistência léxical e interna. $\mathrm{O}$ coeficiente de concordância entre os foi de $90 \%$. O coeficiente Alpha de Cronbach foi de 0,89 para o pré-teste e de 0,88 para o pós-teste.

\section{Tarefas de Controle}

A Habilidade Verbal foi avaliada pelo WISC-III - Escala de Inteligência Wechsler para Crianças, adaptado e padronizado para amostra brasileira (Wechsler, 2002). A memória de trabalho foi medida através do subteste Dígitos do WISC-III, enquanto a atenção concentrada, pelo Teste AC-15 (Boccalandro, 1977).

\section{Procedimentos}

Inicialmente, os adolescentes realizaram, individualmente, as tarefas de controle para avaliação das habilidades verbais e memória de trabalho e, em grupo, para atenção. Os adolescentes realizaram primeiramente o 
teste de Cloze e, dois dias depois realizaram a tarefa de monitoramento. O intervalo entre a aplicação das tarefas de compreensão leitora e monitoramento do pré-teste e aquelas planejadas para o pós-teste foi de 11 semanas. Cada tarefa teve a duração de 50 minutos, ou seja, uma hora-aula. No teste de Cloze, os alunos receberam o texto e instruções para completarem as lacunas em branco do texto com a palavra que melhor pudesse trazer coerência e sentido àquilo que estava sendo lido. Nas tarefas de monitoramento do pré-teste e pós-teste o aluno foi solicitado a ler, a procurar falhas no texto e a corrigi-las, sem nenhuma instrução adicional. Nas tarefas de monitoramento da fase de intervenção, os adolescentes do grupo experimental foram instruídos a monitorar seis textos em seis sessões de 50 minutos, duas vezes por semana. Os jovens deveriam localizar e corrigir os erros no texto, sendo informados do número de erros e da natureza dos mesmos (lexicais e de consistência interna). Ao final de cada etapa, a pesquisadora lia o texto integralmente e, no decorrer da leitura, identificava e discutia com os alunos a natureza do erro. Durante a fase de intervenção, para o grupo controle, foi solicitado que se reunissem, em grupos de seis estudantes, e fizessem um contraponto entre os fatos descritos no texto e suas consequências para o século XXI, elaborando, em seguida, um texto a partir da discussão. As atividades visando ao desenvolvimento do monitoramento foram oferecidas ao grupo controle após o término da pesquisa.

\section{Resultados}

A avaliação do monitoramento foi feita considerandose os processos de detecção e regulação (Baker, 1986). Para cada item, foi atribuído um ponto quando o erro fosse detectado e um ponto se fosse corretamente solucionado, totalizando dois pontos para cada inconsistência inserida no texto. Foi considerada como padrão de resposta, para os erros lexicais, a correção de erros de ortografia, concordância verbal ou pontuação e, para os para os erros de consistência interna, a inserção de palavra ou expressão, igual à do texto original ou sinônima, de forma a restabelecer o sentido do texto. Os escores obtidos na tarefa de Cloze foram resultantes da soma das lacunas preenchidas convencionalmente pelos adolescentes, sendo atribuído um ponto para cada palavra escrita de forma idêntica ou sinônima àquela omitida nos textos. A Tabela 1 apresenta o desempenho dos grupos experimental e controle nas tarefas de monitoramento e Cloze.

Tabela 1

Desempenho dos Grupos Experimental e de Controle nas Tarefas de Controle, Monitoramento e Cloze (pré e pós-teste)

\begin{tabular}{|c|c|c|c|c|c|}
\hline & \multicolumn{4}{|c|}{ Grupos } & \multirow[b]{3}{*}{$t(60)$} \\
\hline & \multicolumn{2}{|c|}{$\begin{array}{c}\text { Grupo Experimental } \\
n=33\end{array}$} & \multicolumn{2}{|c|}{$\begin{array}{c}\text { Grupo Controle } \\
n=29\end{array}$} & \\
\hline & $M$ & $D P$ & $M$ & $D P$ & \\
\hline Idade & 190,06 & 7,31 & 189,31 & 8,78 & 0,37 \\
\hline $\begin{array}{l}\text { Tarefas de Controle } \\
\text { Habilidade Verbal } \\
\text { Atenção } \\
\text { Memória de Trabalho }\end{array}$ & $\begin{array}{l}101,7 \\
41,52 \\
13,85\end{array}$ & $\begin{array}{r}7,2 \\
20,29 \\
20,29\end{array}$ & $\begin{array}{r}103,41 \\
42,79 \\
15,38\end{array}$ & $\begin{array}{r}8,1 \\
3,29 \\
9,5\end{array}$ & $\begin{array}{l}0,88 \\
0,23 \\
0,86\end{array}$ \\
\hline $\begin{array}{l}\text { Pré-teste } \\
\text { Monitoramento } \\
\text { Cloze }\end{array}$ & $\begin{array}{l}0,53 \\
0,57\end{array}$ & $\begin{array}{r}0,2 \\
0,13\end{array}$ & $\begin{array}{l}0,57 \\
0,61\end{array}$ & $\begin{array}{r}0,2 \\
0,13\end{array}$ & $\begin{array}{l}0,87 \\
0,76\end{array}$ \\
\hline $\begin{array}{l}\text { Pós-teste } \\
\text { Monitoramento } \\
\text { Cloze }\end{array}$ & $\begin{array}{l}0,82 \\
0,68\end{array}$ & $\begin{array}{r}0,1 \\
0,14\end{array}$ & $\begin{array}{l}0,68 \\
0,60\end{array}$ & $\begin{array}{l}0,18 \\
0,12\end{array}$ & $\begin{array}{r}3,79 * * \\
2,17 *\end{array}$ \\
\hline
\end{tabular}

Nota. ${ }^{*} p<0,05 ; * * p<0,01$.

Os grupos experimental e controle não apresentaram diferenças significativas em seu desempenho no pré-teste, tanto na tarefa de Cloze, quanto no monitora-mento. No entanto, no pós-teste, há diferenças significativas entre o grupo experimental e controle nas tarefas de monitoramento e de Cloze. Tais resultados mostram que o grupo experimental apresentou um avanço significativo em seu desempenho para monitorar e para compreender textos em relação ao grupo controle. 
Examinamos, então, se o programa de intervenção para o desenvolvimento monitoramento influenciaria de forma significativa o desempenho de leitores menos habilidosos. Os grupos de leitores menos habilidosos foram determinados a partir do desempenho na tarefa de compreensão leitora (tarefa de Cloze) realizadas por todos os alunos antes de iniciada a intervenção. Os leitores menos habilidosos tiveram seu desempenho na tarefa de leitura localizado no quartil inferior da distribuição (25\% dos escores mais baixos). Neste sentido, os grupos experimental e grupo de controle foram compostos por 9 leitores menos habilidosos respectivamente. $\mathrm{O}$ desempenho dos leitores menos habilidosos nos grupos experimental e controle nas diversas tarefas foi comparado através do teste de Mann-Whitney (Tabela 2).

Tabela 2

Média, Desvio-Padrão e U de Mann-Whitney dos Leitores Menos Habilidosos nas Tarefas de Controle, Pré- e PósTestes

\begin{tabular}{|c|c|c|c|c|c|}
\hline & \multicolumn{4}{|c|}{ Leitores Menos Habilidosos } & \multirow[b]{3}{*}{$\begin{array}{r}U-\text { Mann- } \\
\text { Whitney }\end{array}$} \\
\hline & \multicolumn{2}{|c|}{$\begin{array}{c}\text { Grupo Experimental } \\
n=9\end{array}$} & \multicolumn{2}{|c|}{$\begin{array}{c}\text { Grupo de Controle } \\
n=9 \\
\end{array}$} & \\
\hline & $M$ & $D P$ & $M$ & $D P$ & \\
\hline \multicolumn{6}{|l|}{ Tarefas de Controle } \\
\hline Habilidade verbal & 101,11 & 7,34 & 98,78 & 7,42 & -33 \\
\hline Memória de trabalho & 12,89 & 3,18 & 11,56 & 3,58 & -27 \\
\hline Atenção & 36,67 & 16,4 & 36,67 & 23,05 & -37 \\
\hline \multicolumn{6}{|l|}{ Pré-teste } \\
\hline Teste de Cloze & 0,43 & 0,08 & 0,45 & 0,08 & -38 \\
\hline Monitoramento & 0,41 & 0,17 & 0,39 & 0,15 & $-39,5$ \\
\hline \multicolumn{6}{|l|}{ Pós-teste } \\
\hline Teste de Cloze & 0,60 & 0,12 & 0,48 & 0,10 & $16^{*}$ \\
\hline Monitoramento & 0,76 & 0,1 & 0,52 & 0,19 & $9 * *$ \\
\hline
\end{tabular}

Nota. $* p<0,05 ; * p<0,01$.

Leitores menos habilidosos dos grupos experimental e controle não diferiram entre si no que diz respeito as suas habilidades lingüístico-cognitivas ou ao seu desempenho nas tarefas de monitoramento e Cloze do pré-teste. No pós-teste, para os leitores menos habilidosos, o desempenho do grupo experimental foi significativamente melhor do que o do grupo controle nas tarefas de compreensão e de monitoramento, indicando ganhos significativos com a intervenção na compreensão de textos de leitores menos habilidosos.

\section{Discussão}

O presente trabalho objetivou examinar o progresso da compreensão leitora de adolescentes, cursando o ensino médio, através do desenvolvimento da habilidade de monitoramento. $\mathrm{O}$ monitoramento diz respeito à capacidade do leitor de refletir sobre seu próprio entendimento, o que é essencial para a integração da informação processada no ato de ler (Cain \& Oakhill, 2004). Não é, todavia, um processo observável, a menos que algum obstáculo interponha-se à leitura do texto. $\mathrm{O}$ emprego do paradigma de detecção de erros (PDE), através da inserção de transgressões no texto, permitiu a avaliação da habilidade do adolescente em monitorar sua compreensão leitora e a realização de intervenção no sentido de promover o desenvolvimento da própria habilidade de monitoramento.

O melhor desempenho do grupo experimental, no pósteste, na tarefa de monitoramento, demonstrou que o monitoramento é uma habilidade passível de ser treinada e desenvolvida a partir de intervenções específicas (Baker, 1986; Hacker, 1997; Kinnunen \& Vauras, 1995; Oakhill et al., 2005). Quanto à relação entre monitoramento e compreensão leitora, observou-se que os adolescentes do grupo experimental apresentaram diferenças significativas em relação ao grupo controle, no pós-teste, na tarefa de Cloze. A intervenção na habilidade dos alunos para monitorar textos favoreceu a habilidade de reflexão dos adolescentes sobre as informações contidas no texto, ampliando sua capacidade para detectar e modificar informações equívocas ou que dificultassem a compreensão leitora.

Os resultados desse estudo demonstram também que é possível melhorar o desempenho de leitores menos habilidosos, tanto na compreensão textual, quanto na habi- 
lidade para monitorar textos, se eles forem instruídos a refletir e operar sobre sua leitura (Baker, 1986; Thiede et al., 2003). Leitores menos habilidosos revelam-se menos sensíveis a inconsistências encontradas no texto assim como são menos capazes de gerar estratégias para superar as dificuldades percebidas (August, Flavell, \& Clift, 1984; Garner \& Kraus, 1982; Paris \& Myers, 1981). Dessa forma, leitores menos habilidosos mostram menos controle sobre o processo de monitoramento de sua leitura (Baker, 1986). Ao melhorarem sua habilidade em monitorar aquilo que está sendo lido, os adolescentes apresentaram, também, avanços em seu desempenho para compreender textos (Hacker, 1997; Johnson-Glenberg, 2005; Miller, 1985; Oakhill et al., 2005). Durante a intervenção, os adolescentes foram convidados a refletir sobre o seu processo de compreensão, buscando identificar (detecção) e corrigir (regulação) os erros ou contradições encontrados no texto (Baker, 1986; Hacker, 1997; Oakhill et al., 2005). A instrução permitiu ao adolescente desenvolver sua atenção e tornar-se consciente dos obstáculos que impediam o fluxo de sua leitura.

Tal intervenção, por utilizar um procedimento sistemático para realização do monitoramento, teve influência sobre a compreensão inclusive de leitores menos habilidosos. Paris e Myers (1981) sugerem que o paradigma de detecção de erros é um bom indicador do monitoramento porque alguns leitores, ao apresentarem dificuldades para monitorar sua compreensão espontaneamente, podem fazê-lo se forem instruídos para esse fim. A metodologia do PDE permite desenvolver no aprendiz a consciência das dificuldades que prejudicam a compreensão textual, e de que tais obstáculos podem ser superados à medida que o leitor procure dar sentido às informações processadas durante a leitura.

Nesse sentido, a metodologia do paradigma de detecção de erros (PDE) revela-se um procedimento eficaz para o desenvolvimento da habilidade de leitura, permitindo que se possa avaliar tanto a detecção como a regulação e intervir operacionalmente sobre elas, componentes estes envolvidos no processo de monitoramento (Ling, 2000). Os aprendizes são solicitados a, sistematicamente, procurar os erros e inconsistências nos textos lidos, corrigir tais erros e reler o texto. Por fim, coletivamente, os adolescentes passam a identificar falhas, refletem sobre alternativas possíveis de mudança e aplicam tais possibilidades ao texto.

Durante o processo de intervenção, gradativamente, os alunos passaram a ficar mais interessados e atentos à sua leitura. Dessa forma, a utilização dessa metodologia no ensino da leitura como técnica pedagógica pode promover avanços não só na compreensão leitora, mas também na motivação para a leitura. A escola é um dos espaços nos quais se podem viabilizar meios eficazes para o desenvolvimento e ampliação de habilidades envolvidas no ato de ler, através de atividades pedagógicas que promovam o desenvolvimento de habilidades metacognitivas, principalmente, em leitores menos habilidosos.

\section{Referências}

Apolinário, M. R. (2006). História 8 - Ensino fundamental. Projeto Araribá. São Paulo, SP: Moderna.

August, D. L., Flavell, J. H., \& Clift, R. (1984). Comparison of comprehension monitoring of skilled and less skilled readers. Reading Research Quarterly, 20, 39-53.

Baker, L. (1986). Children's effective use of multiple standards of evaluating their comprehension. Journal of Educational Psychology, 76, 585-597.

Boccalandro, N. E. R. (1977). AC-15: Teste de Atenção Concentrada. São Paulo, SP: Vetor.

Boruchovitch, E., Santos, A. A. A., \& Oliveira, K. L. (2007). Análise da fidedignidade entre dois tipos de pontuação do Teste de Cloze. Psicologia em Pesquisa (Juiz de Fora), 1, 41-51.

Brown, A. L. (1978). Knowing when, where, and how to remember: A problem of metacognition. In R. Glaser (Ed.), Advances in Instructional Psychology (pp. 77-165). Hillsdale, NJ: Lawrence Erlbaum.

Brown, A. L., Bransford, J. D., Ferrara, R. A., \& Campione, J. C. (1983). Learning, remembering, and understanding. In P. H. Mussen, J. H. Flavell, \& E. M. Markman (Eds.), Handbook of Child Psychology Cognitive Development ( $4^{\text {nd }}$ ed., Vol. 3, pp. 77-166). New York: John Wiley \& Sons.

Cain, K., \& Oakhill, J. (2004). The develop of comprehension skills. In P. E. Bryant \& T. Nunes (Eds.), Handbook of children's literacy (pp. 155-338). Great Britain, UK: Klover Academic.

Colomer, T., \& Camps, A. (2002). Ensinar a ler, ensinar a compreender. Porto Alegre, RS: Artmed.

Ferreiro, E. (1985). Reflexões sobre a alfabetização. São Paulo, SP: Cortez.

Garner, R., \& Kraus, C. (1982). Good and poor comprehended differences in knowing and regulating reading behaviors. Educational Research Quarterly, 6, 5-12.

Hacker, D. J. (1997). Comprehension monitoring of written discourse across early-to-middle adolescence. Reading and Writing, 9, 207-240.

Instituto Nacional de Estudos e Pesquisas Educacionais Anísio Teixeira, \& Ministério da Educação. (2001). PISA 2000: Relatório Nacional. Brasília, DF. Retrieved October 08, 2007, from http://www.cipedya.com/doc/140404

Johnson-Glenberg, M. (2005). Web-based training of metacognitive strategies for text comprehension: Focus on poor comprehenders. Reading and Writing, 18, 755-786.

Kinnunen, R., \& Vauras, M. (1995). Comprehension monitoring and the level of comprehension in high- and lowachieving primary school children's reading. Learning and Instruction, 5, 143-165.

Kintsch, W. (1988). The role of knowledge in discourse comprehension: A construction-integration model. Psychological Review, 95, 163-182.

Kintsch, W., \& van Dijk, T. A. (1978). Toward a model of text comprehension and production. Psychological Review, 85, 363-394.

Ling, F. (2000). Techniques for assessing comprehension monitoring. Post-Script, 1, 11-32.

Miller, G. E. (1985). The effects of general and specific selfinstruction training on children's comprehension monitoring performances during reading. Reading Research Quarterly, 20, 616-628. 
Oakhill, J. (2005) Editorial. Reading and Writing, 18, iii-vi.

Oakhill, J. V., \& Garnham, A. (1988). Becoming a skilled reader. Oxford, UK: Basil Blackwell.

Oakhill, J., Hartt, J., \& Samols, D. (2005). Levels of comprehension monitoring and working memory in good and poor comprehenders. Reading and Writing, 18, 657-686.

Oliveira, K. L., Boruchovitch, E., \& Santos, A. A. A. (2007). Compreensão de leitura em alunos de sétima e oitava séries do ensino fundamental. Revista Semestral da Associação Brasileira de Psicologia Escolar e Educacional, 11, 41-49.

Paris, S. G., \& Myers, M. (1981). Comprehension monitoring, memory, and study strategies of good and poor readers. Journal of Reading Behaviour, 13, 5-22.

Ribeiro, C. (2003). Metacognição: Um apoio ao processo de aprendizagem. Psicologia: Reflexão e Crítica, 16, 109-116.

Spinillo, A. G. (1994). Estudos de treinamento e variações experimentais. Temas de Psicologia, 3, 43-56.

Thiede, K. W., Anderson, M. C. M., \& Therriault, D. (2003). Accuracy of metacognitive monitoring affects learning of texts. Journal of Educational Psychology, 95, 66-73.

Wechsler, D. (2002). Escala de inteligência Weschsler para crianças: WISC-III. Manual (3. ed). São Paulo, SP: Casa do Psicólogo. 